\title{
Microarray analysis of long non-coding RNA expression profiles uncovers a Toxoplasma- induced negative regulation of host immune signaling
}

Wenquan Liư ${ }^{\dagger}$ Liyang Huang ${ }^{\dagger}$, Qimei Wei, Yu Zhang, Shengnan Zhang, Wenting Zhang, Liya Cai and Shaohui Liang*

\begin{abstract}
Background: Toxoplasma gondii is an obligate intracellular protozoan parasite that can infect mammalian cells and thereby regulate host gene expression. The long non-coding RNAs (IncRNAs) have been demonstrated to be an important class of RNA molecules that regulate many biological processes, including host-pathogen interactions. However, the role of host IncRNAs in the response to T. gondii infection remains largely unknown.

Methods: We applied a microarray approach to determine the differential expression profiles of both IncRNAs and mRNAs in the human foreskin fibroblast (HFF) cells after T. gondii infection. The Gene Ontology and Kyoto Encyclopedia of Genes and Genomes (KEGG) pathway analyses were performed to reveal the potential functions of T. gondii-induced genes. Based on the co-expression networks of IncRNAs and immune-related genes, the role of NONSHAT022487 on the regulation of UNC93B1 related immune signaling was investigated by the knockdown and over-expression of IncRNA in human macrophage derived from the PMA-induced promonocytic cell line THP-1.

Results: Our data showed that 996 IncRNAs and 109 mRNAs in HFF cells were significantly and differentially expressed following $T$. gondii infection (fold change $\geq 5, P<0.05$ ). The results from the GO and KEGG pathway analyses indicated that the mRNAs with differential expression were mainly involved in the host immune response. Remarkably, we identified a novel IncRNA, NONSHAT022487, which suppresses the expression of the immunerelated molecule UNC93B1. After T. gondii infection, NONSHAT022487 impaired the secretion of the cytokines IL-12, TNF-a, IL-1 $\beta$ and IFN- $\gamma$ by downregulating UNC93B1 expression in human macrophage cells.

Conclusions: Our study identified infection-induced IncRNA expression as a novel mechanism by which the Toxoplasma parasite regulates host immune signaling, which advances our understanding of the interaction of $T$. gondii parasites and host cells.
\end{abstract}

Keywords: Toxoplasma gondii, Long non-coding RNA, Microarray, UNC93B1, Immune signaling

\footnotetext{
* Correspondence: Ish@wmu.edu.cn

${ }^{\dagger}$ Equal contributors

Department of Parasitology, Wenzhou Medical University, Wenzhou, Zhejiang

Province, China
} 


\section{Background}

Toxoplasma gondii is an obligate intracellular protozoan parasite that can infect most species of warm-blooded animals around the world [1, 2]. Toxoplasma gondii infection in immunocompetent adults is often subclinical and persists in the life of the host [3]. It can also cause several serious diseases, such as neonatal mortality and fetal infection, which occur in the congenitally infected infants and immunocompromised patients [1, 3, 4]. Manipulating the host environment is a critical step for $T$. gondii to establish its successful invasion and survival in host cells [5-7]. It injects parasite-derived effector molecules into the host cell to interfere with their defenses during the invasion [8]. Immediately following the invasion, $T$. gondii establishes a specialized parasitophorous vacuole (PV) within the host cell cytoplasm [9]. The PV protects the parasites against lysosomal destruction and provides a residence in which the parasites can replicate within the host cells [10]. Meanwhile, the intracellular parasites can change the host biological process to maintain its persistence, such as by inhibiting apoptosis [11, 12], inducing autophagy [13], controlling the cell cycle [14] and regulating immune signaling [15].

Long non-coding RNAs (lncRNAs), which have a length of longer than 200 nucleotides and lack a protein-coding capacity, represent a significant proportion of the human transcriptome [16]. Thousands of mammalian lncRNAs have identified their regulatory function in various biological processes, including cell development [17], chromatin modification [16] and immune regulation [18]. LncRNAs have gained great interest for their wide variety of regulatory roles [19]. They can interact with RNA, DNA, protein or microRNAs to regulate transcription, splicing, nucleic acid degradation and translation $[16,20]$. The dysregulation of lncRNA expression can lead to cell functional deficiencies that contributes to a variety of diseases, such as developmental defects [21], tumorigenesis [22] and autoimmune diseases [23]. Recent studies have shown that viral or bacterial infection can change the expression profiles of lncRNAs in the host, which indicated that lncRNAs are involved in the regulation of host-pathogen interactions, and even determine the outcome of infection [24-27]. Several lines of emerging evidence have demonstrated that small non-coding RNAs (microRNAs) are involved in the host- $T$. gondii interaction [28-31]. However, the role of lncRNAs in the response to the Toxoplasma parasite is still unclear.

In this study, we explored the differential expression profiles of both lncRNAs and mRNAs in human foreskin fibroblast (HFF) cells after T. gondii infection. Our data showed that the differentially expressed mRNAs were correlated with host immune signaling. We also identified an lncRNA, NONSHAT022487, which suppresses UNC93B1-related immune signaling in $T$. gondii-infected human macrophage cells. Our study reveals a role of lncRNAs induced by $T$. gondii infection in regulating host immune responses, which advances our understanding of the interaction of $T$. gondii parasites and host cells.

\section{Methods \\ Cell culture}

The human foreskin fibroblast cell line (HFF, CRL-2522) and THP-1(TIB-202) cells were obtained from ATCC, and the human embryonic kidney 293 cell line was kindly provided by Jianming Wu (Wenzhou Medical University, Wenzhou, China). HFF and 293 cells were cultured in Dulbecco's Modified Eagle Medium (DMEM) supplemented with 10\% heatinactivated fetal bovine serum (FBS, Gibco, LA, USA), 2 mM L-glutamine, penicillin $(100 \mathrm{U} / \mathrm{ml})$ and streptomycin $(100 \mu \mathrm{g} / \mathrm{ml})$. THP-1 is a human promonocytic cell line that was used as the in vitro model for studying $T$. gondii-induced immune modulation [32]. THP-1 cells were cultured in RPMI 1640 medium (Gibco, LA, USA) supplemented with 10\% FBS, $2 \mathrm{mM}$ L-glutamine, penicillin $(100 \mathrm{U} / \mathrm{ml})$ and streptomycin $(100 \mu \mathrm{g} / \mathrm{ml})$. Prior to parasite infection, THP-1 cells were plated in 6-well flat-bottom plates (Falcon, NY, USA) and primed with $0.5 \mu \mathrm{M}$ PMA (Sigma-Aldrich, Boston, MA, USA) for $3 \mathrm{~h}$. The primed cells were then washed with 1640 medium and allowed to adhere overnight to generate macrophages. The THP-1-derived macrophages were used for subsequent experiments. HFF, 293 and THP-1 cells were maintained at $37{ }^{\circ} \mathrm{C}$ and $5 \% \mathrm{CO}_{2}$.

\section{Parasite infection}

The ME49 strain of Toxoplasma gondii was multiplied in HFF cells as previously described [33]. Briefly, the $T$. gondii ME49 strain was multiplied in HFF cells and cultured in DMEM containing 10\% FBS and $2 \mathrm{mM} \mathrm{L-}$ glutamine, penicillin $(100 \mathrm{U} / \mathrm{ml})$ and streptomycin $(100 \mu \mathrm{g} / \mathrm{ml})$. The tachyzoites were isolated from the infected HFF monolayers using syringe lysis and washed with DMEM twice. The tachyzoite cultures were further purified using a $5 \mu \mathrm{m}$ pore size polycarbonate membrane (Millipore, Bedford, MA, USA) to remove the host cell debris, and resuspended in DMEM with 10\% FBS for use in the following infections.

HFF cells were infected with purified tachyzoites with a multiplicity of infection (MOI) of 0.2. Six h after parasite inoculation, the cultures were washed twice with PBS to remove any non-adherent $T$. gondii and cultured at 5\% $\mathrm{CO}_{2}$ and $37{ }^{\circ} \mathrm{C}$ for $48 \mathrm{~h}$. Both uninfected and inactivated T. gondii-treated HFF cells were used as controls. Toxoplasma gondii parasites were inactivated in a $60{ }^{\circ} \mathrm{C}$ water bath for $20 \mathrm{~min}$. The death of the parasites was then tested by in vitro passage in HFF cells. Cell samples were harvested and stored at $-80{ }^{\circ} \mathrm{C}$ for subsequent analysis. 


\section{RNA preparation}

Total RNA was extracted from different cell sample using TRIzol Reagent (Invitrogen, CA, USA), according to the manufacturer's protocol. The RNA was cleaned up with an RNasey Mini Kit (Qiagen, Boston, MA, USA) and then treated with DNase I (Invitrogen) to remove the genomic DNA. The RNA quality and quantity were assessed by denaturing agarose gel electrophoresis and a Du530 spectrophotometer (Beckman, Heidelberg, Germany).

\section{Microarray analysis}

The samples for the microarray were prepared according to the protocol by the manufacturer (Agilent Technology, Santa Clara, CA, USA). One hundred ng of total RNA from each sample was amplified and transcribed into fluorescent cDNAs using the random primer method. The labeled cDNAs were purified by an RNeasy Extraction Kit (Qiagen). Human IncRNA array V4.0 (Arraystar, Rockville, MD, USA), which contains 40,173 human lncRNAs and 20,730 mRNAs, was employed in this study. The Agilent Array Software v.10.7 was used for the microarray analysis. The microarray hybridization was performed by Lian chuan Bio-tech (Shanghai, China). Each sample was performed with three biological replicates. Both differentially expressed lncRNAs and mRNAs with statistical significance between the two groups were identified through $P$-value, false discovery rate (FDR) and fold-change filtering. The lncRNAs and mRNAs with Fold change $\geq 2(P<0.05)$ were considered statistically significant in microarry analysis. The microarray data have been deposited in the NCBI Gene Expression Omnibus (GEO), and the GEO accession number is GSE92603. Hierarchical clustering and combined analyses were performed by Lian chuan Bio-tech (Shanghai, China) using Agilent GeneSpring GX software (version 11.5.1).

\section{Real-time quantitative PCR analysis}

Following RNA extraction, the first-strand cDNA was synthesized using the PrimeScript RT Reagent Kit with MMLV reverse transcriptase (Invitrogen) according to the protocol. Real-time quantitative PCR (RT-qPCR) was performed using Master Mix (Promega, San Luis Obispo, CA, USA) on an ABI7300 Fluorescent Quantitative PCR (Applied Biosystems, Foster City, CA, USA). The RTqPCR cycles were: $95^{\circ} \mathrm{C}$ for $30 \mathrm{~s}$, followed by 40 cycles at $95{ }^{\circ} \mathrm{C}$ for $5 \mathrm{~s}$ and $60{ }^{\circ} \mathrm{C}$ for $5 \mathrm{~s}$. GAPDH was included as an internal control. The relative levels of gene expression were calculated using the $2^{-\Delta \Delta} \mathrm{Ct}$ method. Each sample was repeated in three independent experiments. The primers for the lncRNAs and mRNAs (Additional file 1: Table S1) were designed and synthesized in BGI (Shanghai, China).

\section{Bioinformatics analysis}

Gene ontology (GO) analysis was performed to identify the potential biological functions based on the differentially expressed mRNAs (www.geneontology.org). It covers three classifications, including biological processes, cellular components and molecular functions. Fisher's exact test was applied to classify the GO categories. Enrichment scores were calculated based on $\log _{10}(P$-value). The lower the $P$-value, the more significant the GO term $(P<0.05$ is required). The Kyoto Encyclopedia of Genes and Genomes (KEGG) pathway analysis (http://www.kegg.jp) was also adopted to map the differentially expressed genes. The enrichment and statistical calculations were similar to the GO analysis. $P<0.05$ was considered statistically significant. The co-expression network of the lncRNA and mRNA was constructed using Cytoscape software.

\section{shRNA plasmid construction and knockdown}

ShRNA knockdown was performed using adenovirus transduction as described previously [34]. The small hairpin RNA (shRNA) for lncRNA NONHSAT022487 (Transcript ID: NONHSAT022487.2, http://www.noncode.org) was synthesized (GenePharma, Shanghai, China). The shRNA targeting sequence for NONHSAT022487 is 5'CCA ATA CCG CAG GGT CTC CGA-3'. The shRNA sequence for GFP (5'-CCC GCA AGC TGA CCC TGA AGT TCT TCA AGA GAG AAC TTC AGG GTC AGC TTG CTT TTT GGA AA-3') was included as a control. The shRNA sequences were cloned into a shuttle vector pHBAd-U6-GFP (Hanheng, Shanghai, China) and were co-transfected with the backbone vector pBHGlox(delta)E1,3Cre into 293 cells to package the recombinant adenovirus using Lipofectamine 2000 (Life Technologies, Carlsbad, CA, USA) according to the manufacturer's protocol. After 10 days of culture, the cells were collected, frozen, thawed twice at temperatures between $-70{ }^{\circ} \mathrm{C}$ and $37^{\circ} \mathrm{C}$, and centrifuged at $2000 \times g$ for $5 \mathrm{~min}$ at $4{ }^{\circ} \mathrm{C}$. The first-generation recombinant adenovirus in the supernatant was collected and used to infect 293 cells for two rounds of propagation. Then, high-titer recombinant adenovirus was harvested and stored at $-80{ }^{\circ} \mathrm{C}$ until use.

For knockdown studies, HFF and THP-1 monocytes were seeded at $1 \times 10^{6}$ cells per well in a 6 -well plate, individually. The next day, the cells were infected with recombinant adenovirus expressing shNONHSAT022487 (sh-NONHSAT022487), and cultured for $48 \mathrm{~h}$. Infection efficiency was monitored by observing the number of GFP-positive cells under a fluorescence microscope. The cell samples were harvested for RT-qPCR and Western blotting. The adenovirus-expressing shRNA for GFP was taken as the control (sh-control).

\section{Overexpression of NONHSAT022487}

For overexpression of NONHSAT022487, the sequence of NONHSAT022487 was amplified using the following primers: forward (5'-AAG TCT AGA GAG AGG GTG CAC GTG ACG CTG G-3') and reverse (5'-CGG GGT 
ACC TTA AAG AAG GAA GAG GTT TAT TCA GC-3'). Then, the NONHSAT022487 gene was inserted into the multiple cloning site of pcDNA3.1(-) using $\mathrm{Xba \textrm {I }}$ and $\mathrm{Kp} n \mathrm{I}$ restriction endonucleases. The recombinant vector pcDNA3.1-NONHSAT022487 (pc-NONHSAT022487) was confirmed by sequencing in BGI (Shanghai, China). HFF and THP-1 cells were transfected with the pc-NONHSAT022487 construct using the TransIT ${ }^{\circ}$-LT1 Transfection Reagent (Mirus Bio., Madison, WI, USA) following the instructions by the manufacturer. The pcDNA3.1 empty plasmid was included as a control (pc-control). After $48 \mathrm{~h}$ of transfection, the cells were harvested for qPCR and Western blotting.

\section{Western blotting}

Cells were lysed in RIPA buffer (Beyotime, Shanghai, P.R. China) supplemented with a protease inhibitor cocktail (Roche, Foster City, CA, USA). The concentration of proteins was detected using an enhanced BCA Protein Assay kit (Beyotime). Equal amounts of protein samples were submitted to SDS-PAGE and Western blotting. Briefly, the proteins were transferred onto PVDF membranes (Bio-Rad,Hercules, CA, USA) and blocked with 5\% nonfat dry milk in TBST buffer $(25 \mathrm{mM}$ Tris- $\mathrm{HCl}, 125 \mathrm{mM}$ $\mathrm{NaCl}, 0.1 \%$ Tween 20) for $2 \mathrm{~h}$ at $37^{\circ} \mathrm{C}$. Then, the rabbit anti-humanUNC93B1 primary antibody (Abcam, Cambridge, MA, USA) was incubated at $4{ }^{\circ} \mathrm{C}$ overnight. After washing 3 times with TBST buffer, the membranes were incubated with Peroxidase-conjugated anti-rabbit IgG secondary antibody (Abcam) for $1 \mathrm{~h}$. GAPDH was included as an internal control. The Western blots were visualized, and the densitometric measurements of the band intensity was performed using Quantity One software.

\section{Cytokine ELISA}

THP-1 cells were primed in the macrophage with $0.5 \mu \mathrm{M}$ PMA, and then were infected by adenovirus shNONHSAT022487 or transfected with pcNONHSAT022487 construct. After $6 \mathrm{~h}$ of infection or transfection, the culture medium was replaced with fresh medium, and the supernatant was collected after $48 \mathrm{~h}$ by centrifugation at 3000× rpm for $20 \mathrm{~min}$ at $4{ }^{\circ} \mathrm{C}$. For $T$. gondii infection, the PMAinduced THP-1 cells were incubated with $T$. gondii at an MOI of 1 after infection with shNONHSAT022487 or transfection with pcNONHSAT022487 plasmid for $24 \mathrm{~h}$. The shRNA-GFP and pCDNA3.1 empty plasmids were taken as controls, respectively. The culture medium was replaced with fresh medium after T. gondii infection for $6 \mathrm{~h}$. After culturing for $48 \mathrm{~h}$, the supernatant was collected by centrifugation. Three biological replicates were performed for each sample. The levels of IL-12, TNF- $\alpha$, IL- $1 \beta$ and IFN- $\gamma$ were measured, respectively, using commercially available ELISA kits (R\&D Systems, Minneapolis, MN, USA) according to the instructions by the manufacturer. Cytokine concentrations in the samples were calculated using standard curves generated from recombinant cytokines, and the results were expressed in picograms per milliliter.

\section{Statistical analysis}

Statistical analyses were performed using SPSS 17.0 software package. All results were expressed as the mean with standard deviation (SD) from three independent biological replicates for each treatment. Student's t-test was applied to compare the difference between the two groups. Moreover, the FDR was calculated to correct the $P$-value. $P<0.05$ was considered statistically significant.

\section{Results}

Differential expression of IncRNAs after $T$. gondii infection To explore the lncRNA expression profiles of HFF cells in response to $T$. gondii infection, microarray analyses were performed among the uninfected, inactivated $T$. gondii-treated and T. gondii-infected HFF cells. The inactivated group was used as a control to rule out the possibility that the host lncRNAs were regulated by the dead parasites. The lncRNAs with an expression change of more than two-fold were selected as differentially expressed candidates. We detected 6044 and 6436 lncRNAs in the T. gondii-infected group when compared with the uninfected group and the inactivated group individually (Table 1). Notably, the expression of 1206 lncRNAs (973 increased and 233 decreased) in the $T$. gondii-infected group displayed over five-fold changes, when compared with the uninfected group (Fig. $1 \mathrm{~b}$ and Table 1 , the list of lncRNAs is shown in Additional file 2: Table S2). There were 1316 differentially expressed lncRNAs (1022 increased and 294 decreased) with more than five-fold changes in the infected group when compared with the inactivated group (Fig. 1b and Table 1, the list of lncRNAs is shown in Additional file 3: Table S3). By only considering the lncRNAs that were actively regulated by $T$. gondii infection, 996 lncRNAs (800 upregulated and 196 downregulated) were selected as the significantly differentially expressed candidates (fold change $\geq 5$ ) for the further study (Fig. 1a, b).

To validate the microarray data above, twenty lncRNAs (10 upregulated and 10 downregulated) were randomly selected from the candidates with significant differential expression for RT-qPCR detection. The RT-qPCR results showed that, after T. gondii infection, 9 of 10 upregulated lncRNAs

Table 1 Numbers of differentially expressed IncRNAs in the $T$. gondii-infected HFF cells

\begin{tabular}{llllll}
\hline IncRNAs & \multicolumn{2}{l}{ T. gondii vs uninfected } & & \multicolumn{2}{l}{ T. gondii vs inactivated } \\
\cline { 2 - 3 } \cline { 6 - 6 } & FD $\geq 2.0$ & $F D \geq 5.0$ & & $F D \geq 2.0$ & $F D \geq 5.0$ \\
\hline Upregulated & 4525 & 973 & & 4873 & 1022 \\
Downregulated & 1519 & 233 & & 1563 & 294 \\
Total & 6044 & 1206 & & 6436 & 1316 \\
\hline
\end{tabular}

Abbreviations: T. gondii, T. gondii-infected HFF cells; uninfected, uninfected HFF cells; inactivated, inactivated T. gondii-infected HFF cells; FD, fold changes 


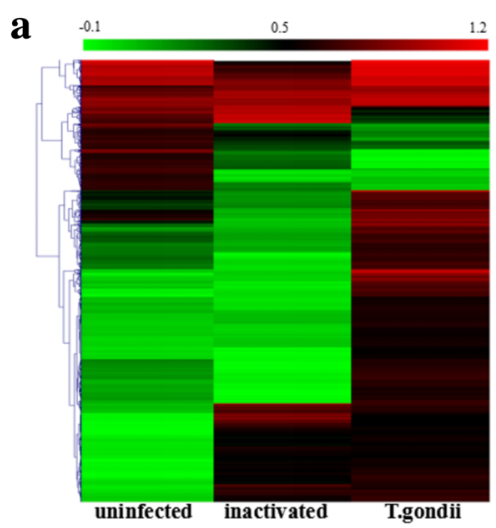

c



b

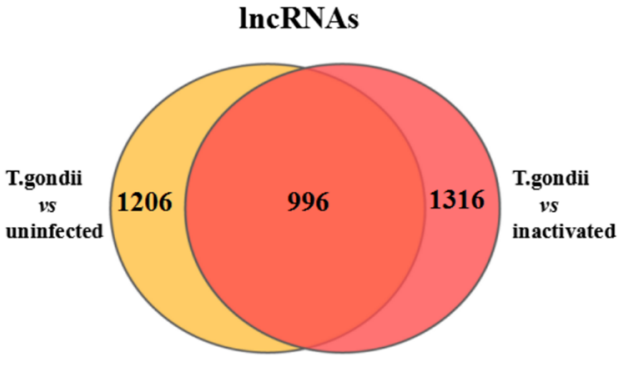

d

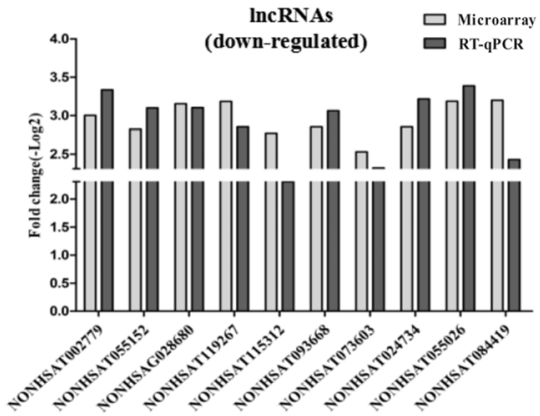

Fig. 1 Differential expression of IncRNAs after T. gondii infection. a The hierarchical clustering of significantly differentially expressed IncRNAs (fold change $\geq 5, P<0.05$ ) between the uninfected HFF cells (uninfected), the inactived $T$. gondii-infected HFF cells (inactivated) and the T. gondii-infected HFF cells (T. gondii). In the heat map, red indicates the high relative expression, and green indicates the low relative expression. $\mathbf{b}$ Venn diagrams indicate the number of total and overlapping IncRNAs with the significant differential expression in the T. gondii group, compared with the uninfected and inactivated groups, respectively. $\mathbf{c}$ and $\mathbf{d}$ Real time quantitative PCR (RT-qPCR) validation of the upregulated and downregulated IncRNAs (fold change $\geq 5, P<0.05$ ) from the microarray data

and all of the 10 downregulated lncRNAs exhibited the same expression patterns as the microarray data (Fig. 1c, d).

Differential expression of mRNAs after $T$. gondii infection Microarray analysis was also performed to explore the expression profiles of mRNAs in HFF cells after T. gondii infection. There were 1808 and 1924 mRNAs that showed differential expression (fold change $\geq 2$ ) after $T$. gondii infection when compared with the uninfected group and the inactivated group, respectively (Table 2). Furthermore, we detected 143 and 186 mRNAs with a higher fold change

Table 2 Numbers of differentially expressed mRNAs in the $T$. gondii-infected HFF cells

\begin{tabular}{|c|c|c|c|c|}
\hline \multirow[t]{2}{*}{ mRNAs } & \multicolumn{2}{|c|}{ T. gondii vs uninfected } & \multicolumn{2}{|c|}{ T. gondii vs inactivated } \\
\hline & $\mathrm{FD} \geq 2.0$ & $F D \geq 5.0$ & $F D \geq 2.0$ & $F D \geq 5.0$ \\
\hline Upregulated & 1322 & 125 & 1427 & 159 \\
\hline Downregulated & 486 & 18 & 497 & 27 \\
\hline Total & 1808 & 143 & 1924 & 186 \\
\hline
\end{tabular}

Abbreviations: T. gondii, T. gondii-infected HFF cells; uninfected, uninfected HFF cells; inactivated, inactivated $T$. gondii-infected HFF cells; FD, fold changes (fold change $\geq 5$ ) in the T. gondii-infected group compared with the uninfected and inactivated group, respectively (Table 2, the list of mRNAs is shown in Additional file 4: Table S4 and Additional file 5: Table S5). By excluding the host mRNAs that were regulated by the dead parasites, 109 mRNAs (82 upregulated and 27 downregulated) were selected as significant differential mRNA candidates for subsequent studies (Fig. 2a, b).

To validate the mRNA expression from the microarray analyses, 10 mRNAs (5 upregulated and 5 downregulated) were randomly selected for RT-qPCR detection. The qPCR results showed that, in the $T$. gondii-infected HFF cell, 4 of 5 upregulated mRNAs displayed the same expression trends as the microarray data (Fig. 2c). For the downregulated mRNAs, 3 of 5 mRNAs exhibited more than a five-fold reduction after $T$. gondii infection (Fig. 2d).

\section{Gene ontology, KEGG pathway and co-expression network analyses}

Gene ontology (GO) analysis was carried out to predict the potential biological functions of the host mRNAs that were 


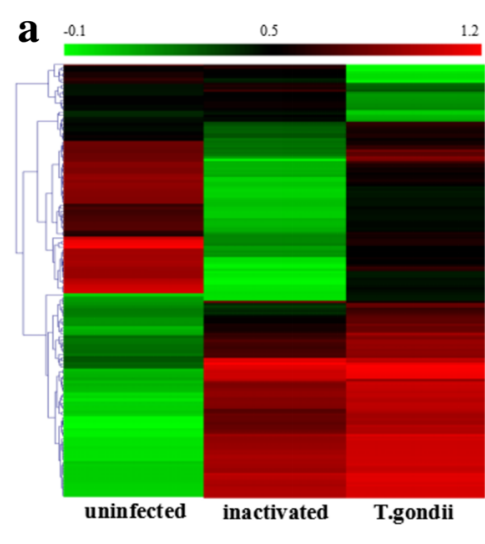

\section{b}

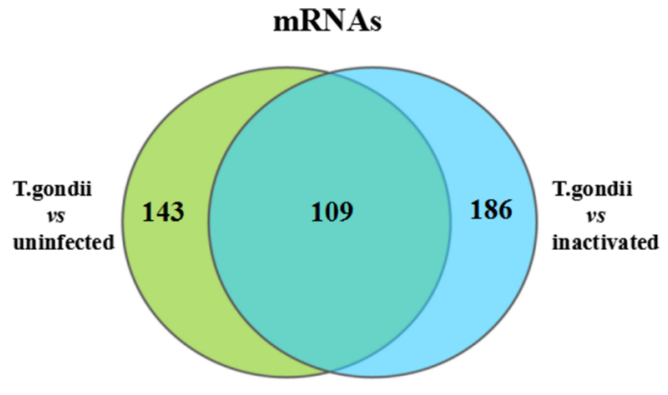

c $\begin{array}{cl}\text { mRNAs } & \square \text { Microarray } \\ \text { (up-regulated) } & \square \text { RT-qPCR }\end{array}$

d

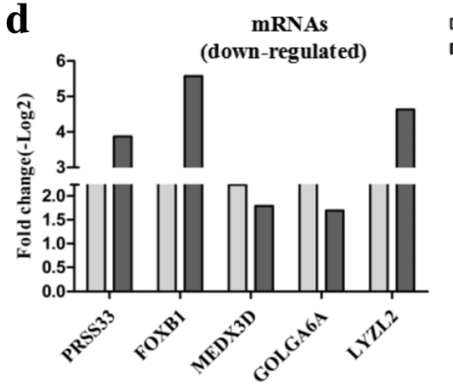

Fig. 2 Differential expression of mRNAs after T. gondii infection. a The hierarchical clustering of significantly differentially expressed mRNAs (fold change $\geq 5, P<0.05$ ) between the uninfected HFF cells (uninfected), the inactivated T. gondii-infected HFF cells (inactivated) and the T. gondii-infected HFF cells ( $\mathrm{T}$. gondii). In the heat map, red indicates high relative expression, and green indicates low relative expression. $\mathbf{b}$ Venn diagrams indicate the number of total and overlapping mRNAs with significant differential expression in the T. gondii group compared with the uninfected and inactivated groups, respectively. $\mathbf{c}$ and $\mathbf{d}$ Real-time quantitative PCR (RT-qPCR) validation of the upregulated and downregulated mRNAs (fold change $\geq 5, P<0.05$ ) from the microarray data

regulated by $T$. gondii infection. Based on the biological processes in the gene ontology classification, the significant differential mRNAs (fold change $\geq 5$ ) from the microarray analyses were classified into different functional categories. The GO analysis showed that the three most enriched GO terms with upregulated mRNAs were the "adaptive immune response", "positive regulation of interferon production" and "regulation of immune response to tumor cell" (Fig. 3a). The downregulated mRNAs were mainly involved in the "regulation toll-like receptor", "virushost interaction" and "cytokine receptor activity" (Fig. 3b). These results suggested that both upregulated and downregulated mRNAs were specifically correlated with the host immune response.

To further understand the predicted biological functions of the mRNAs with differential expression, the Kyoto Encyclopedia of Genes and Genomes (KEGG) pathway analysis was performed. The results indicated that the upregulated mRNAs mainly participated in the following signaling pathways: "Fc receptor signaling pathway", "Gprotein receptor signaling pathway" and "insulin-like receptor signaling pathway" (Fig. 3c). The downregulated mRNAs were significantly enriched in several immune signaling pathways, such as "Toll such as signaling pathway",
"Cytokine-mediated signaling pathway" and "MAPK signaling pathway" (Fig. 3d). These data indicated that the innate immune signaling in the host may be the main target regulated by $T$. gondii infection.

To determine the potential interaction between lncRNAs and immune-related genes during $T$. gondii infection, the coding-non-coding gene $(\mathrm{CNC})$ co-expression network was constructed based on the correlation analysis. The lncRNAs were found to be involved in the expression of several genes coding for immune-related proteins, including LTA, IL17C and UNC93B1 (Fig. 3e). The additional co-expression network of lncRNAs and immune-related genes, such as IL17RA, LST1, TNFRSF14 and AIF1, are shown in Additional file 6: Figure S1. For example, 39 lncRNAs, including NONHSAT144418, were positively correlated with the expression of the LTA gene, which encodes a protein of the tumor necrosis factor family; and 4 lncRNAs, including NONHSAG006167, were negatively correlated with the $I l$ $17 c$ gene coding for the cytokine IL17C that is restricted to activated $\mathrm{T}$ cells. Interestingly, we found that UNC93B1, which has been identified as one of the critical immunerelated molecules in mediating the host defenses against $T$. gondii infection [35, 36], was correlated with a novel lncRNA, NONHSAT022487 (Fig. 3e). Additionally, the 


\section{a GO terms for up-regulated genes}

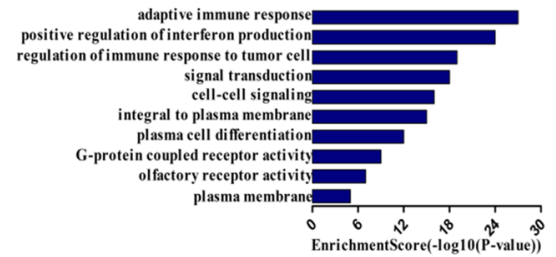

C KEGG Pathway for up-regulated genes

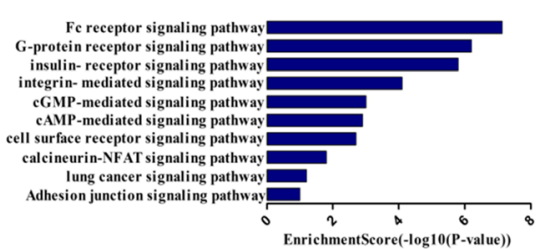

b GO terms for down-regulated genes

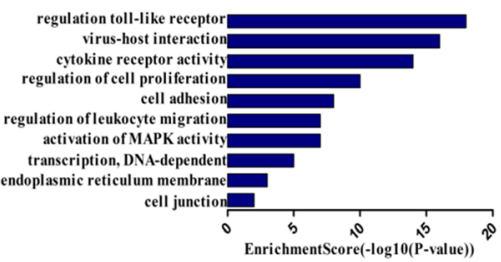

d KEGG Pathway for down-regulated genes

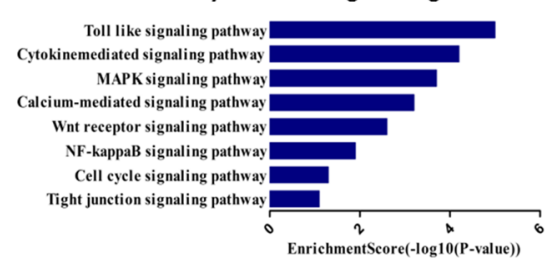

e Co-expression networks of IncRNAs and mRNAs
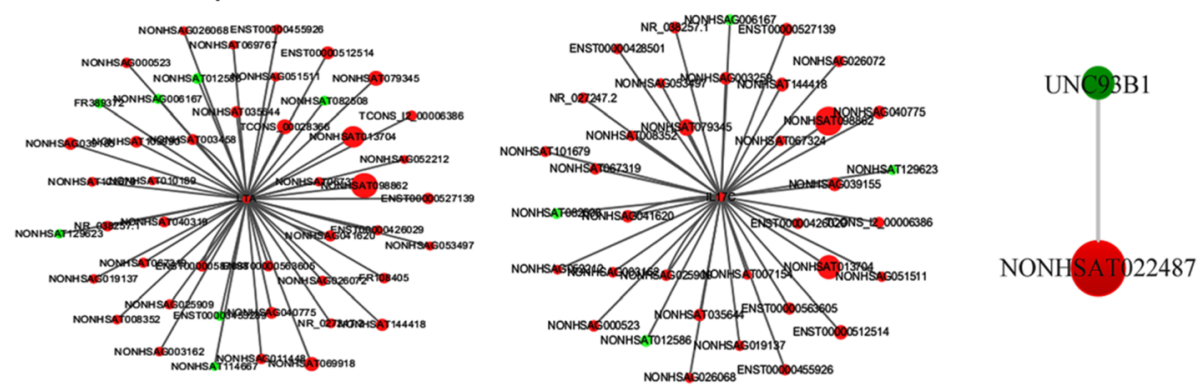

Fig. 3 GO terms, KEGG pathway and Co-expression network analyses of differentially expressed mRNAs induced by T. gondii infection. The significant $\mathrm{GO}$ terms for the upregulated genes (a) and for the downregulated genes (b) in the HFF cells after T. gondii infection. The GO terms were filtered in accordance with $P<0.05$ and FDR $<0.05$. The most significant KEGG pathways for the upregulated genes (c) and for the downregulated genes (d) in the HFF cells after T. gondii infection. e The co-expression networks of the IncRNAs and mRNAs were constructed using Cytoscape software. The upregulated IncRNAs and mRNAs are shown by the red rectangle. The green rectangles represent the downregulated IncRNAs and mRNAs

co-expression network analysis suggested that lncRNA NONHSAG006167 may be involved in the regulation of UNC93B1-related immune signaling.

\section{NONHSAT022487 suppress the expression of UNC93B1}

To examine the expression patterns of the lncRNA NONHSAT022487 and the mRNA UNC93B1, HFF and THP-1 cells were infected with $T$. gondii, respectively. The transcriptional levels of both NONHSAT022487 and UNC93B1 were analyzed by RT-qPCR. The protein expression of UNC93B1 was detected by Western blotting. Compared with both the uninfected and inactivated T. gondii-infected HFF cells, the transcriptional level of NONHSAT022487 was increased by more than 30 -fold after T. gondii infection (Fig. 4a), whereas both mRNA and protein levels of UNC93B1 were decreased by over 10-fold in the T. gondiiinfected HFF cells (Fig. 4a, b). The similar increased level of NONHSAT022487 transcription and decreased level of UNC93B1 expression were also observed in the T. gondiiinfected THP-1 cells (Fig. 4c, d).
To determine the regulation of IncRNA NONHSAT022487 on the expression of UNC93B1, NONHSAT022487 was knocked down in both HFF and THP-1 cells by transfection with the shRNA-NONHSAT022487 lentiviral plasmid (Additional file 7: Figure S2). Compared with the control plasmid, the relative transcriptional level of NONHSAT022487 was markedly reduced by $78.26 \%$ in $\operatorname{HFF}\left(t_{(4)}=6.453, P=\right.$ $0.0097)$ and $67.43 \%$ in THP- 1 cells $\left(t_{(4)}=5.527, P=0.0054\right)$ at $48 \mathrm{~h}$ post-transfection (Fig. $5 \mathrm{a}, \mathrm{d}$ ). In contrast, the relative transcriptional level of UNC93B1 was significantly increased by 5.5 -fold in HFF $\left(t_{(4)}=5.013, P=0.0068\right)$ and 3.75-fold in THP-1 cells $\left(t_{(4)}=4.761, P=0.009\right)$ after knock-down of lncRNA NONHSAT022487 (Fig. 5b, e). The protein level of UNB93B1 was also increased by 6-fold in HFF (Fig. 5c) and 4-fold in THP-1 cells (Fig. 5f). These results indicated that knockdown of NONHSAT022487 significantly promoted the expression of the UNC93B1 gene.

In addition, we over-expressed NONHSAT022487 in both HFF and THP-1 cells by the transfection of the pcDNA3.1 expression construct containing NONHSAT022487 into these cells. The relative transcription level of NONHSAT022487 

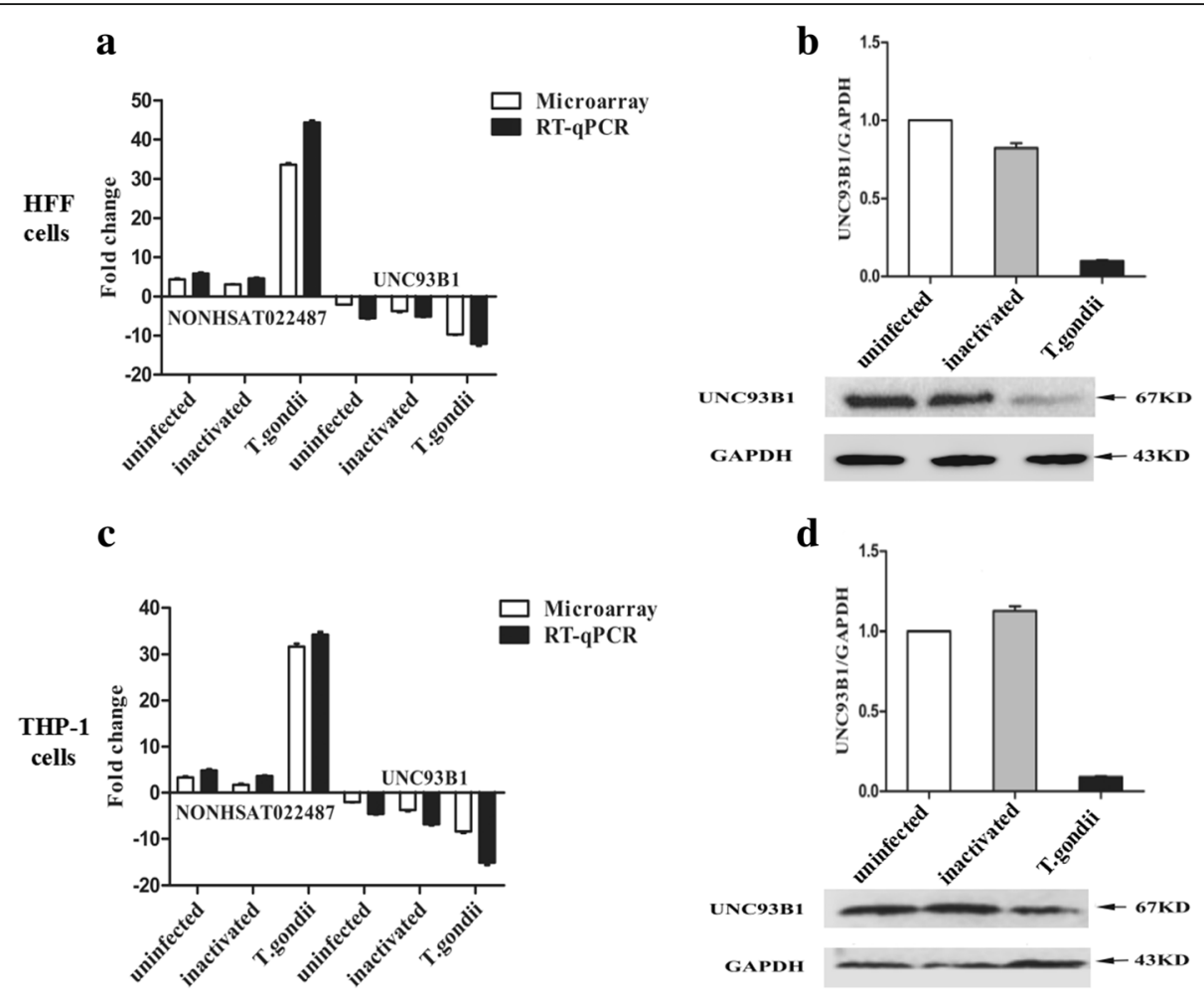

Fig. 4 The expression patterns of NONHSAT022487 and UNC93B1 after T. gondii infection. a Microarray and RT-qPCR analyses showing the transcriptional levels of IncRNA NONHSAT022487 and the UNC93B1 gene in various HFF cells as indicated: uninfected, uninfected HFF cells; inactivated, inactivated T. gondii-infected HFF cells; T. gondii, T. gondii-infected HFF cells. b Western blot image showing the protein level of UNC93B1 in various HFF cells after T. gondii infection. GAPDH was used for internal normalization. The ratio of UNC93B1/GAPDH indicated the relative expression changes in various treated HFF cells according to Western blot. c As described in $\mathbf{a}$, except that THP-1 cells were used. $\mathbf{d}$ As described in $\mathbf{b}$, except that THP-1 cells were used

was enhanced by 8 -fold in HFF $\left(t_{(4)}=4.851, P=0.008\right)$ and 10 -fold in THP-1 cells $\left(t_{(4)}=5.218, P=0.006\right)$ at $48 \mathrm{~h}$ posttransfection (Fig. 6a, d). As expected, the levels of transcription and protein expression of UNC93B1 were decreased by over 5-fold in both HFF $\left(\left(t_{(4)}=6.319, P=0.0037\right)\right.$ and THP-1 cells $\left(t_{(4)}=5.913, P=0.0043\right)$ after over-expression of lncRNA NONHSAT022487 (Fig. 6b,c e, f), when compared with the control plasmid. These results indicated that the overexpression of lncRNA NONHSAT 022487 significantly inhibited the expression of UNC93B1 gene.

\section{NONHSAT022487 mediates the secretion of cytokines by negatively regulating UNC93B1 expression}

UNC93B1 has been demonstrated to be critical for inducing cytokine production and autonomous control of Toxoplasma replication in macrophages $[35,36]$. Since NONHSAT022487 can suppress the UNC93B1 expression, we wanted to examine the role of NONHSAT022487 in cytokine secretion. In the uninfected cells, the secretion levels of IL-12 $\left(t_{(4)}=3.305, P=0.033\right)$, TNF- $\alpha\left(t_{(4)}=3.417\right.$, $P=0.028), \mathrm{IL}-1 \beta\left(t_{(4)}=3.429, P=0.027\right)$ and IFN- $\gamma\left(t_{(4)}=\right.$ $3.607, P=0.023)$ were significantly upregulated after $48 \mathrm{~h}$ of transfection with shRNA-NONHSAT022487, when compared with the shRNA control (Fig. 7). Furthermore, these cells that over-expressed NONHSAT022487 exhibited a decrease in the secretion of cytokines, despite the lack of significance (Fig. 7).

After T. gondii infection, the production of cytokines IL12 , TNF- $\alpha$, IL-1 $\beta$ and IFN- $\gamma$ was enhanced in the infected cells, when compared with the uninfected cells. Especially for the $T$. gondii infected cells with transfection of shNONHSAT022487, the production of these cytokines was significantly enhanced when compared with those transfected with shRNA control (IL-12: $t_{(4)}=3.395, P=0.03$; TNF- $\alpha: \quad\left(t_{(4)}=7.923, \quad P=0.0014 ; \quad\right.$ IL-1 $\beta: \quad t_{(4)}=7.195, \quad P=$ 0.0019 ; IFN- $\left.\gamma: t_{(4)}=6.301, P=0.0034\right)$. In contrast, overexpression of lncRNA NONHSAT022487 followed by infection with $T$. gondii impaired the secretion of the cytokines $\operatorname{IL}-1 \beta\left(t_{(4)}=2.721, P=0.051\right)$ and IFN- $\gamma\left(t_{(4)}=3.015, P=\right.$ 0.041 ), and a more significant inhibition of secretion was observed in IL-12 $\left(t_{(4)}=6.301, P=0.0034\right)$ and TNF- $\alpha\left(t_{(4)}=\right.$ 6.625, $P=0.0028$ ) in these cells (Fig. 7). Collectively, these results suggested that the IncRNA NONHSAT022487 mediates the secretion of the cytokines IL-12, TNF- $\alpha$, IL- $1 \beta$ and IFN- $\gamma$ by negatively regulating the expression of UNC93B1 and that $T$. gondii infection can upregulate the expression of NONHSAT022487, thereby impairing the UNC93B1regulated secretion of cytokines. 


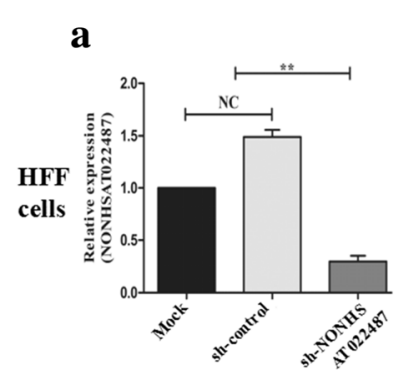

b

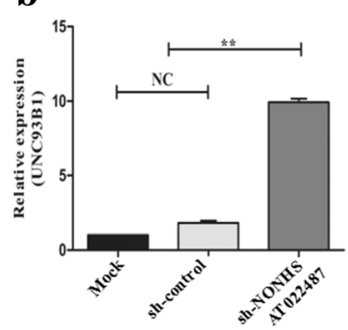

d

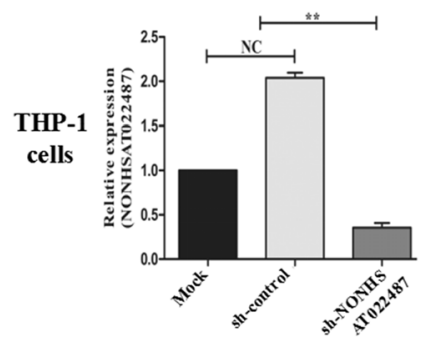

e

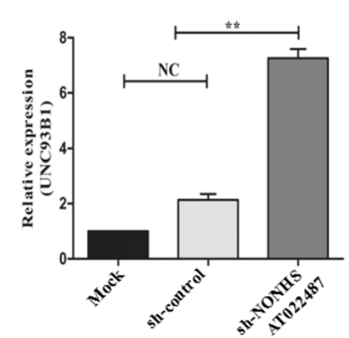

C

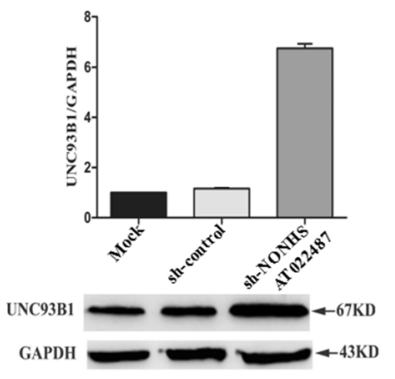

f

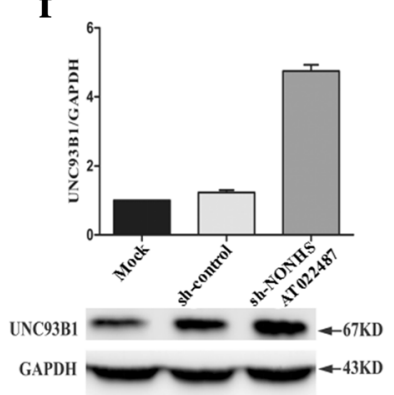

Fig. 5 Upregulated expression of the UNC93B1 gene by knock down of NONHSAT022487. a RT-qPCR analysis showing the transcriptional levels of NONHSAT022487 in various HFF cells as indicated. Cells were transfected with the shRNA-NONHSAT022487 lentiviral plasmid (sh-NONHSAT02248) or shRNA-control plasmid (sh-control). b As described in a, except that the transcriptional level of the UNC93B1 gene was detected. c Western blotting image showing the protein expression of UNC93B1 in various HFF cells as indicated. GAPDH was used for internal normalization. The ratio of UNC93B1/GAPDH indicated the relative expression changes in various treated HFF cells according to Western blotting. $\mathbf{d}$ As described in a, except that THP-1 cells were used. e As described in $\mathbf{b}$, except that THP-1 cells were used. $\mathbf{f}$ As described in $\mathbf{c}$, except that THP-1 cells were used. Data are the mean with standard deviations (SD) from three independent biological replicates. ${ }^{*} P<0.05,{ }^{*} P<0.01$. Abbreviations: NC, no significant changes

\section{Discussion}

Toxoplasma gondii belongs to the phylum Apicomplexa, which contains many other important clinical and veterinary pathogens, such as Plasmodium, Cryptosporidium and Eimeria [37]. Since apicomplexans can only propagate within host cells, the regulatory cell biological function is critically important for their survival and pathogenesis [38]. Previous studies on the interaction of apicomplexan parasites and the host have largely focused on proteincoding genes [33, 39-41]. However, a number of recent studies have suggested that long ncRNAs (lncRNAs) were also involved in host-pathogens interactions [25, 27, 28, 42]. For instance, Mycobacterium tuberculosis (Mtb) infection altered the IncRNA and mRNA expression profiles in the human macrophage [42]. The analysis of the host transcription following SARS-CoV infection revealed that lncRNAs were associated with the host response to virus infection and altered innate immune signaling [27]. Our study of host long ncRNAs (lncRNAs) in response to $T$. gondii infection provides new insight into the regulating mechanism of the host gene expression by the Apicomplexan parasites.

In our study, the expression profiles of both lncRNAs and mRNAs in $T$. gondii-infected HFF cells were fully explored by microarray. Compared with the uninfected
HFF cells, the expression profiles of both lncRNAs and mRNAs were profoundly altered in the $T$. gondii-infected HFF cells. The heat-killed parasite-infected HFF cells were used as a control to exclude the genes and pathways that were activated by dead parasites. There were redundant 392 lncRNAs and 116 mRNAs that were detected in the inactivated group compared with the uninfected group. They thus considered that the host lncRNAs and mRNAs were regulated by the dead parasites. A total of 996 lncRNAs and 109 mRNAs (fold change $\geq 5$ ) were identified as the differential expression candidates and subsequently analyzed by GO term and KEGG pathway analysis. Interestingly, we found that the most enriched GO terms in the biological processes that targeted the upregulated genes are the adaptive immune response and the positive regulation of interferon production. However, the most enriched GO terms and KEGG pathways involved in the downregulated mRNAs are the Toll-like receptor and signaling pathways. It is believed that $T$. gondii possesses multiple means to down-modulate the production of pro-inflammatory cytokines [43]. One of the mechanisms for this downregulation is that $T$. gondii infection inhibits the intracellular signaling cascades, such as NF- $\mathrm{kB}$ and STAT1, within the infected cells $[44,45]$. 

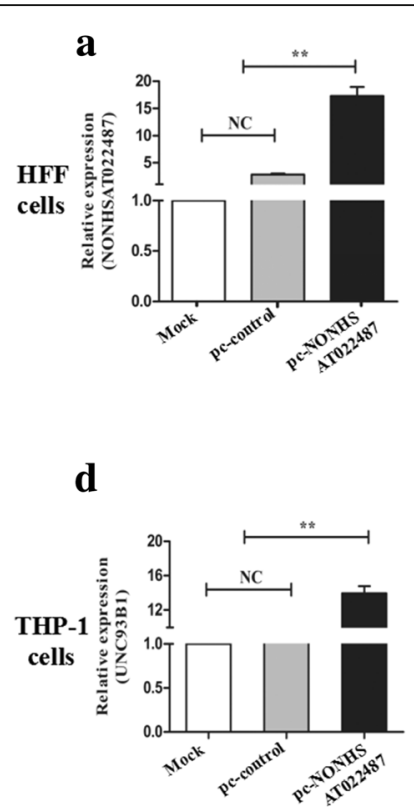
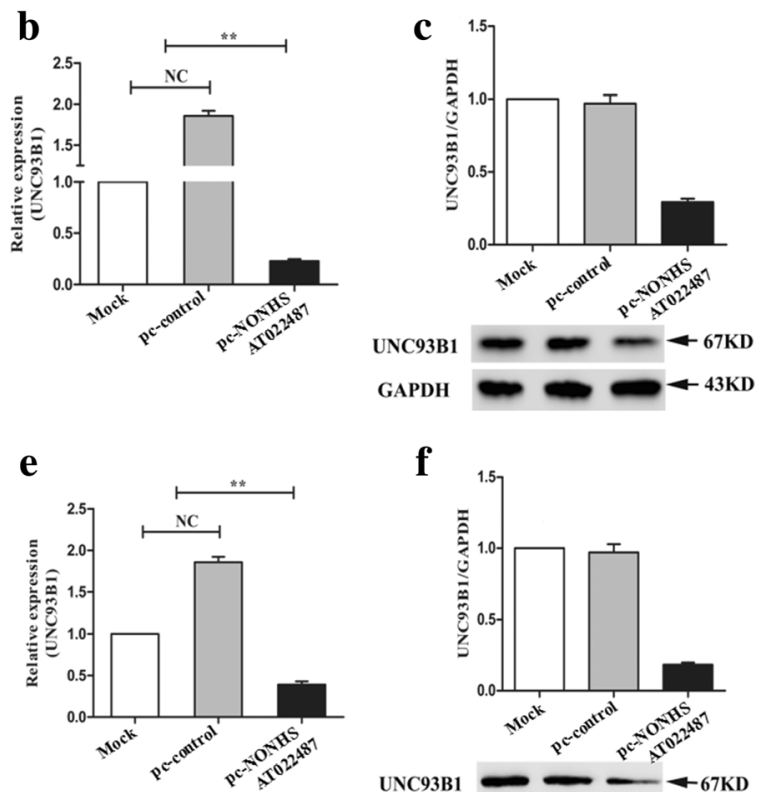

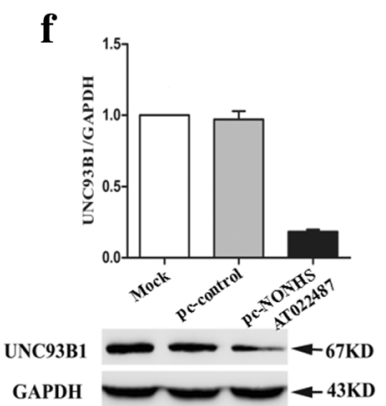

Fig. 6 Downregulated expression of the UNC93B1 gene by over-expression of NONHSAT022487. a RT-qPCR analysis showing the transcriptional level of NONHSAT022487 in various HFF cells as indicated. Cells were transfected with pcDNA3.1-NONHSAT022487 (pc-NONHSAT022487) or pcDNA control plasmid (pc-control). $\mathbf{b}$ As described in $\mathbf{a}$, except that the transcriptional level of UNC93B1 was detected. $\mathbf{c}$ Western blotting image showing the protein expression of UNC93B1 in various HFF cells as indicated, the GAPDH was used for the internal normalization. The ratio of UNC93B1/GAPDH indicated the relative expression changes in various treated HFF cells according to the Western blot. $\mathbf{d}$ As described in $\mathbf{a}$, except that THP-1 cells were used. e As described in $\mathbf{b}$, except that THP-1 cells were used. $\mathbf{f}$ As described in c, except that THP-1 cells were used. Data are the mean with standard deviations (SD) from three independent biological replicates. ${ }^{*} P<0.05,{ }^{*} P<0.01$. Abbreviations: NC, no significant changes

Toll-like receptors (TLRs) are pathogen-associated molecular pattern (PAMP) recognition receptors that play a central role in macrophage activation and the control of parasitic infections $[36,46]$. The $T$. gondii-derived component profilin can be recognized by TLR11and TLR12 and induce IL-12 production that limits the cyst burden in $T$. gondii-infected mice [47, 48]. The UNC93B1, a multitransmembrane endoplasmic reticulum-resident protein, is required for proper TLR localization and signaling in both humans and mice $[49,50]$. UNC93B1 can facilitate translocation of TLR (TLR3, TLR7 and TLR9) from the endoplasmic reticulum to the Golgi $[51,52]$ and mediates the host immune responses to infection with murine cytomegalovirus [53], as well as several intracellular protozoan parasites $[35,54]$. A deficiency in the functional UNC93B1 protein abolished TLR dependent cytokine secretion by macrophages and attenuated immune responses against intracellular parasite infection, including Trypanosoma cruzi [54] and T. gondii [35, 36]. Mice lacking functional UNC93B1 result in the impaired production of IL-12, IFN$\gamma$ and enhanced $T$. gondii tachyzoite replication [35, 36]. However, the role of UNC93B1 in intracellular parasite growth appears to be independent of TLR function [35].

Our results suggested that NONSHAT022487 can suppress the expression of the immune-related molecule
UNC93B1 by lncRNA knockdown and over-expression experiments. Meanwhile, the RT-qPCR results in Figs. 5 and 6 indicate that there is a non-significant difference in the expression of NONHSAT022487 and UNC93B1 between the mock and the controls. Considering that both lncRNA NONHSAT022487 and UNC93B1 are involved in innate immune responses, it is possible that their different expression maybe affected by nonspecific treatment, such as transfection with GFP shRNA and pcDNA empty vector. Our further study also demonstrated that NONSHAT022487 can regulate the secretion of the cytokines IL-12, TNF- $\alpha$, IL-1 $\beta$ and IFN- $\gamma$ after T. gondii infection. To survive successfully, the Toxoplasma parasite actively regulates the host immune response to downregulate the production of proinflammatory cytokines, which could be harmful to the parasite $[15,32]$. For example, T. gondii infection inhibits the host cell transcriptional response to IFN- $\gamma$ [55]. Meanwhile, T. gondii-infected murine splenic lymphocytes could impair the capacity of these cells to produce cytokines and immunoglobulin secretions [43]. This regulation of the host immune response is critical for the parasite to establish a chronic infection. On the other hand, the host has to downregulate the immune responses shortly after initial upregulation to control damages to self. Several lines of emerging evidence have indicated that lncRNAs 

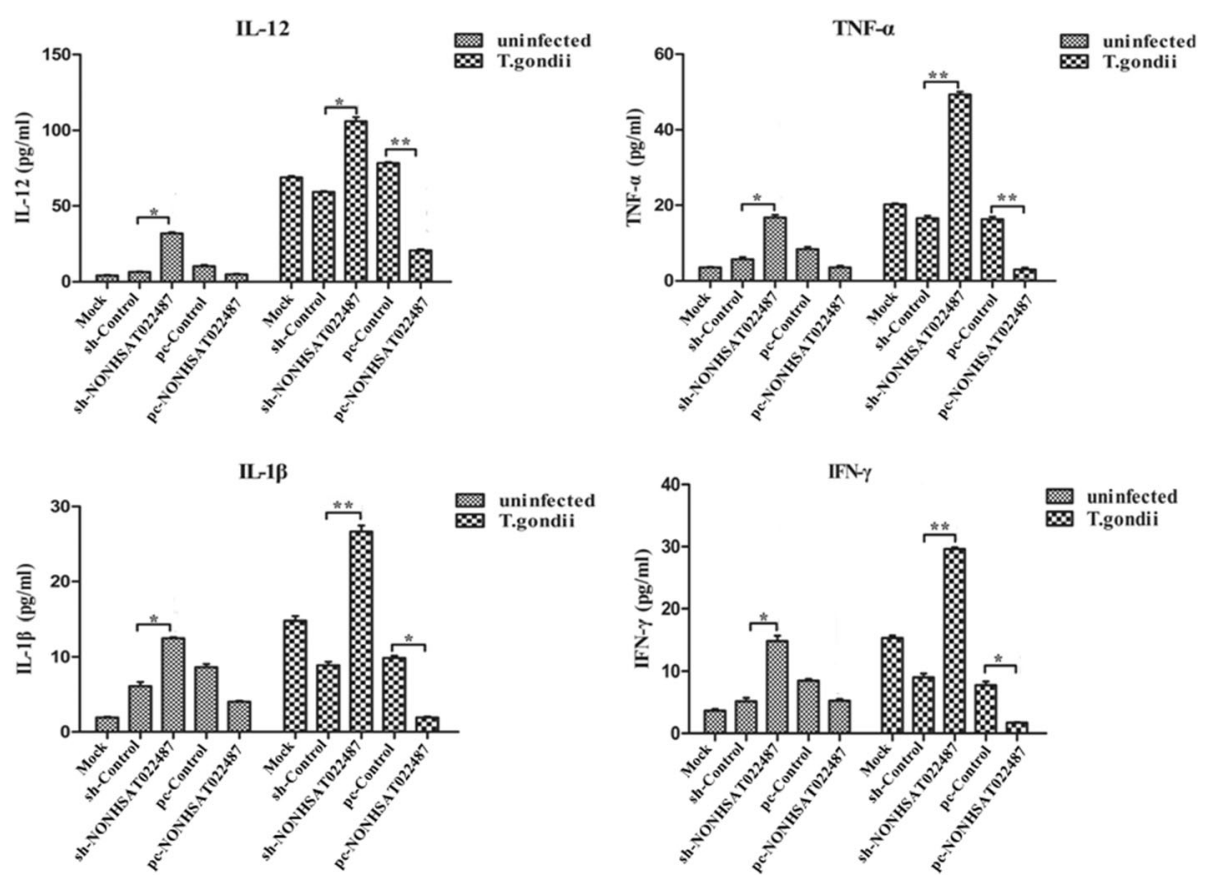

Fig. 7 NONHSAT022487 mediates the secretion of cytokines in T. gondii-infected macrophages cells. The secretion of the cytokines IL-12, TNF-a, IL-1 $\beta$ and IFN- $\gamma$ in the supernatant of various THP-1-derived macrophage cells from before (uninfected) or after T. gondii infection (T. gondii) were assessed by ELISA. Cells were transfected with shRNA-NONHSAT022487 lentiviral plasmid (sh-NONHSAT022487), shRNA control plasmid (sh-Control), pcDNA3.1-NONHSAT022487 plasmid (pc-NONHSAT022487) or pcDNA3.1 control plasmid (pc-Control) as indicated. Data are the mean with standard deviations (SD) from three independent biological replicates. ${ }^{*} P<0.05,{ }^{*} P<0.01$

function in the regulation of the mammalian innate and adaptive immune responses [23, 56]. For example, lncRNACox2 has been identified to regulate the TLR signaling pathway [56], while lncRNA PACER (p50-assocated COX-2 extragenic RNA) acts as a decoy molecule in the NF- $\mathrm{kB}$ signaling pathway [23]. Therefore, further studies will be needed to elucidate the role of lncRNAs in Toxoplasma infection and immune regulation.

\section{Conclusions}

In this study, we investigated the differential expression profiles of lncRNAs and mRNAs in T. gondii infected-HFF cells and revealed that the differential expressed genes were mainly involved in the host immune response. Significantly, we identified the lncRNAs as regulatory molecules involved in the host immune signaling to $T$. gondii infection, which advances our understanding of the interaction of $T$. gondii parasites and host cells.

\section{Additional files}

Additional file 1: Table S1. A list of primer sequences used for the real-time $\mathrm{qPCR}$ detection. (XLSX $11 \mathrm{~kb}$ )

Additional file 2: Table S2. A list of significantly differentially expressed IncRNAs between the T. gondii infected and uninfected groups. (XLSX $63 \mathrm{~kb}$ )
Additional file 3: Table S3. A list of significantly differentially expressed IncRNAs between the T. gondii infected and inactivated groups. (XLSX 68 kb)

Additional file 4: Table S4. A list of significantly differentially expressed mRNAs between the T. gondii infected and uninfected groups. (XLSX $15 \mathrm{~kb}$ )

Additional file 5: Table S5. A list of significantly differentially expressed mRNAs between the T. gondii infected and uninfected groups. (XLSX $17 \mathrm{~kb}$ )

Additional file 6: Figure S1. The additional interaction network of IncRNAs and immune-related genes induced by T. gondii infection. (TIFF 1644 kb)

Additional file 7: Figure S2. Transfection of shRNA-NONHSAT022487 into HFF and THP-1 cells. (TIFF 972 kb)

\section{Abbreviations}

HFF cells: human foreskin fibroblast cells; inactivated: inactivated T. gondiitreated cells; infected: T. gondii-infected cells; IncRNAs: long non-coding RNAs; MOI: multiplicity of infection; PV: parasitophorous vacuole; RTQPCR: real-time quantitative PCR; uninfected: uninfected cells

\section{Acknowledgements}

We thank Xiaoguang Chen for kindly providing the ME49 strain. We are grateful to Zhijiang Yan and Feng Tan for the critical review of the manuscript, and thank "American Journal Experts" for the language improvement.

\section{Funding}

This work was supported by the National Natural Science Foundation of China (81572029), the Commonweal Technology Application Project of Zhejiang Province (2015C33101), the Natural Science Foundation of Zhejiang Province (LY13C080001) and the Commonweal Technology Application Project of Wenzhou City (Y20170022). The funders had no role in study design, data collection and interpretation, or the decision to submit the work for publication. 


\section{Availability of data and materials}

The microarray data supporting the conclusions of this article are available in the NCBI Gene Expression Omnibus (GEO) with the accession number GSE92603.

\section{Authors' contributions}

SL conceived and designed the study. WL, LH, QW, YZ, SZ, WZ and LC performed the experiments, $\mathrm{WL}$ and $\mathrm{LH}$ analyzed the data and drafted the manuscript. SL critically revised the manuscript. All authors read and approved the final manuscript.

\section{Ethics approval and consent to participate}

Not applicable.

\section{Consent for publication}

Not applicable.

\section{Competing interests}

The authors declare that they have no competing interests.

\section{Publisher's Note}

Springer Nature remains neutral with regard to jurisdictional claims in published maps and institutional affiliations.

\section{Received: 25 July 2017 Accepted: 2 February 2018} Published online: 12 March 2018

\section{References}

1. Montoya JG, Liesenfeld O. Toxoplasmosis. Lancet. 2004:363(9425):1965-76.

2. Zhou P, Chen Z, Li HL, Zheng H, He S, Lin RQ, Zhu XQ. Toxoplasma gondii infection in humans in China. Parasit Vectors. 2011:4:165.

3. Weiss LM, Dubey JP. Toxoplasmosis: a history of clinical observations. Int J Parasitol. 2009:39(8):895-901.

4. Saeij JP, Boyle JP, Coller S, Taylor S, Sibley LD, Brooke-Powell ET, et al. Polymorphic secreted kinases are key virulence factors in toxoplasmosis. Science. 2006;314(5806):1780-3.

5. Balder IJ, Manger ID, Boothroyd JC. Microarray analysis reveals previously unknown changes in Toxoplasma gondii-infected human cells. J Biol Chem. 2001;276(26):24223-31.

6. Carruthers VB. Host cell invasion by the opportunistic pathogen Toxoplasma gondii. Acta Trop. 2002;81(2):111-22.

7. Zhou DH, Zhao FR, Huang SY, Xu MJ, Song HQ, Su C, Zhu XQ. Changes in the proteomic profiles of mouse brain after infection with cyst-forming Toxoplasma gondii. Parasit Vectors. 2013;6:96.

8. Dubremetz JF. Rhoptries are major players in Toxoplasma gondii invasion and host cell interaction. Cell Microbiol. 2007:9(4):841-8.

9. Hakansson S, Charron AJ, Sibley LD. Toxoplasma evacuoles: a two-step process of secretion and fusion forms the parasitophorous vacuole. EMBO J. 2001;20(12):3132-44

10. Zhao YO, Khaminets A, Hunn JP, Howard JC. Disruption of the Toxoplasma gondii parasitophorous vacuole by IFNgamma-inducible immunity-related GTPases (IRG proteins) triggers necrotic cell death. PLoS Pathog. 2009;5(2):e1000288.

11. Nash PB, Purner MB, Leon RP, Clarke P, Duke RC, Curiel TJ. Toxoplasma gondii-infected cells are resistant to multiple inducers of apoptosis. J Immunol. 1998:160(4):1824-30.

12. Goebel S, Gross U, Inhibition LCG. Of host cell apoptosis by Toxoplasma gondii is accompanied by reduced activation of the caspase cascade and alterations of poly(ADP-ribose) polymerase expression. J Cell Sci. 2001;114(Pt 19):3495-505.

13. Wang Y, Weiss LM, Orlofsky A. Host cell autophagy is induced by Toxoplasma gondii and contributes to parasite growth. J Biol Chem. 2009; 284(3):1694-701.

14. Molestina RE, El-Guendy N, Sinai AP. Infection with Toxoplasma gondii results in dysregulation of the host cell cycle. Cell Microbiol. 2008;10(5): 1153-65.

15. Denkers EY. From cells to signaling cascades. Manipulation of innate immunity by Toxoplasma gondii. FEMS Immunol Med Microbiol. 2003;39(3):193-203.

16. Angrand PO, Vennin C, Le Bourhis X, Adriaenssens E. The role of long noncoding RNAs in genome formatting and expression. Front Genet. 2015;6:165.
17. Peng L, Paulson A, Li H, Piekos S, He X, Li L, Zhong XB. Developmental programming of long non-coding RNAs during postnatal liver maturation in mice. PLoS One. 2014;9(12):e114917.

18. Imamura K, Akimitsu N. Long non-coding RNAs involved in immune responses. Front Immunol. 2014;5:573.

19. Stachurska A, Zorro MM, van der Sijde MR, Withoff S. Small and long regulatory RNAs in the immune system and immune diseases. Front Immunol. 2014:5:513.

20. Engreitz JM, Ollikainen N, Guttman M. Long non-coding RNAs: spatial amplifiers that control nuclear structure and gene expression. Nat Rev Mol Cell Biol. 2016;17(12):756-70.

21. Grote P, Wittler L, Hendrix D, Koch F, Wahrisch S, Beisaw A, et al. The tissuespecific IncRNA Fendrr is an essential regulator of heart and body wall development in the mouse. Dev Cell. 2013;24(2):206-14.

22. Lin C, Wang Y, Wang Y, Zhang S, Yu L, Guo C, Xu H. Transcriptional and posttranscriptional regulation of HOXA13 by IncRNA HOTTIP facilitates tumorigenesis and metastasis in esophageal squamous carcinoma cells. Oncogene. 2017;36(38):5392-406.

23. Satpathy Ansuman T, Chang Howard Y. Long noncoding RNA in hematopoiesis and immunity. Immunity. 2015;42(5):792-804.

24. Ma Y, Ouyang J, Wei J, Maarouf M, Chen JL. Involvement of host noncoding RNAs in the pathogenesis of the influenza virus. Int J Mol Sci. 2016;18(1):e39.

25. Yin Z, Guan D, Fan Q, Su J, Zheng W, Ma W, Ke C. IncRNA expression signatures in response to enterovirus 71 infection. Biochem Biophys Res Commun. 2013:430(2):629-33.

26. Scaria V, Pasha A. Long non-coding RNAs in infection biology. Front Genet. 2013:3.308

27. Peng $X$, Gralinski L, Armour CD, Ferris MT, Thomas MJ, Proll S, et al. Unique signatures of long noncoding RNA expression in response to virus infection and altered innate immune signaling. MBio. 2010;1 (5):00206-10.

28. Cai Y, Shen J. Modulation of host immune responses to Toxoplasma gondii by microRNAs. Parasite Immunol. 2017;39(2):12417.

29. Zeiner GM, Norman KL, Thomson JM, Hammond SM, Boothroyd JC. Toxoplasma gondii infection specifically increases the levels of key host microRNAs. PLoS One. 2010;5(1):e8742.

30. He JJ, Ma J, Wang JL, Xu MJ, Zhu XQ. Analysis of miRNA expression profiling in mouse spleen affected by acute toxoplasma gondii infection. Infect Genet Evol. 2016; 37:137-142

31. Xu M-J, Zhou D-H, Nisbet AJ, Huang S-Y, Fan Y-F, Zhu X-Q. Characterization of mouse brain microRNAs after infection with cyst-forming Toxoplasma gondii. Parasit Vectors. 2013;6:154.

32. Gov L, Karimzadeh A, Ueno N, Lodoen MB. Human innate immunity to Toxoplasma gondii is mediated by host caspase-1 and ASC and parasite GRA15. MBio. 2013:4(4):00255-13.

33. Melo MB, Nguyen QP, Cordeiro C, Hassan MA, Yang N, McKell R, et al. Transcriptional analysis of murine macrophages infected with different Toxoplasma strains identifies novel regulation of host signaling pathways. PLoS Pathog. 2013:9(12):e1003779.

34. Chen XG, Lv QX, Construction ZXQ. Of recombinant adenovirus ad-rat PLCg2-shRNA and successful suppression of PLCg2 expression in BRL-3A cells. Genet Mol Res. 2016;15(2):1-10.

35. Melo MB, Kasperkovitz P, Cerny A, Konen-Waisman S, Kurt-Jones EA, Lien E, et al. UNC93B1 mediates host resistance to infection with Toxoplasma gondii. PLoS Pathog. 2010:6(8):e1001071.

36. Pifer R, Benson A, Sturge CR, Yarovinsky F. UNC93B1 is essential for TLR11 activation and IL-12-dependent host resistance to Toxoplasma gondii. J Biol Chem. 2011:286(5):3307-14.

37. Kim K, Weiss LM. Toxoplasma gondii: the model apicomplexan. Int J Parasitol. 2004:34(3):423-32.

38. Sullivan WJ Jr, Jeffers V. Mechanisms of Toxoplasma gondii persistence and latency. FEMS Microbiol Rev. 2012;36(3):717-33.

39. He JJ, Ma J, Elsheikha HM, Song HQ, Zhou DH, Zhu XQ. Proteomic profiling of mouse liver following acute Toxoplasma gondii infection. PLoS One. 2016 11(3):e0152022

40. Saeij JP, Coller S, Boyle JP, Jerome ME, White MW, Boothroyd JC. Toxoplasma co-opts host gene expression by injection of a polymorphic kinase homologue. Nature. 2007:445(7125):324-7.

41. Xu X, Dong Y, Abraham EG, Kocan A, Srinivasan P, Ghosh AK, et al. Transcriptome analysis of Anopheles stephensi-Plasmodium berghei interactions. Mol Biochem Parasitol. 2005;142(1):76-87. 
42. Yang $X$, Yang J, Wang J, Wen $\mathrm{Q}$, Wang $\mathrm{H}$, He J, et al. Microarray analysis of long noncoding RNA and mRNA expression profiles in human macrophages infected with Mycobacterium tuberculosis. Sci Rep. 2016;6:38963.

43. Guk SM, Kook J, Jeon YH, Choi JH, Han ET, Shin EH, Chai JY. Suppressed cytokine and immunoglobulin secretions by murine splenic lymphocytes infected in vitro with Toxoplasma gondii tachyzoites. J Parasitol. 2005;91(2):467-70.

44. Zimmermann S, Murray PJ, Heeg K, Dalpke AH. Induction of suppressor of cytokine signaling-1 by Toxoplasma gondii contributes to immune evasion in macrophages by blocking IFN-gamma signaling. J Immunol. 2006;176(3):1840-7.

45. Shapira S, Speirs K, Gerstein A, Caamano J, Hunter CA. Suppression of NFkappaB activation by infection with Toxoplasma gondii. J Infect Dis. 2002; 185(Suppl 1):S66-72.

46. Leng J, Butcher BA, Egan CE, Abi Abdallah DS, Denkers EY. Toxoplasma gondii prevents chromatin remodeling initiated by TLR-triggered macrophage activation. J Immunol. 2009;182(1):489-97.

47. Koblansky AA, Jankovic D, Oh H, Hieny S, Sungnak W, Mathur R, et al. Recognition of profilin by toll-like receptor 12 is critical for host resistance to Toxoplasma gondii. Immunity. 2013;38(1):119-30.

48. Raetz M, Kibardin A, Sturge CR, Pifer R, Li H, Burstein E, et al. Cooperation of TLR12 and TLR11 in the IRF8-dependent IL-12 response to Toxoplasma gondii profilin. J Immunol. 2013;191(9):4818-27.

49. Huh JW, Shibata T, Hwang M, Kwon EH, Jang MS, Fukui R, et al. UNC93B1 is essential for the plasma membrane localization and signaling of toll-like receptor 5. Proc Natl Acad Sci USA. 2014;11(19):7072-7.

50. Fukui R, Saitoh S, Kanno A, Onji M, Shibata T, Ito A, et al. Unc93B1 restricts systemic lethal inflammation by orchestrating toll-like receptor 7 and 9 trafficking. Immunity. 2011;35(1):69-81.

51. Kim YM, Brinkmann MM, Paquet ME, Ploegh HL. UNC93B1 delivers nucleotide-sensing toll-like receptors to endolysosomes. Nature. 2008; 452(7184):234-8.

52. Brinkmann MM, Spooner E, Hoebe K, Beutler B, Ploegh HL, Kim YM. The interaction between the ER membrane protein UNC93B and TLR3, 7, and 9 is crucial for TLR signaling. J Cell Biol. 2007;177(2):265-75.

53. Crane MJ, Gaddi PJ, Salazar-Mather TP. UNC93B1 mediates innate inflammation and antiviral defense in the liver during acute murine cytomegalovirus infection. PLoS One. 2012;7(6):e39161.

54. Caetano BC, Carmo BB, Melo MB, Cerny A, dos Santos SL, Bartholomeu DC, et al. Requirement of UNC93B1 reveals a critical role for TLR7 in host resistance to primary infection with Trypanosoma cruzi. J Immunol. 2011; 187(4):1903-11.

55. Gavrilescu LC, Butcher BA, Del Rio L, Taylor GA, Denkers EY. STAT1 is essential for antimicrobial effector function but dispensable for gamma interferon production during Toxoplasma gondii infection. Infect Immun. 2004;72(3):1257-64.

56. Carpenter S, Aiello D, Atianand MK, Ricci EP, Gandhi P, Hall LL, et al. A long noncoding RNA mediates both activation and repression of immune response genes. Science. 2013;341(6147):789-92.

\section{Submit your next manuscript to BioMed Central and we will help you at every step:}

- We accept pre-submission inquiries

- Our selector tool helps you to find the most relevant journal

- We provide round the clock customer support

- Convenient online submission

- Thorough peer review

- Inclusion in PubMed and all major indexing services

- Maximum visibility for your research

Submit your manuscript at www.biomedcentral.com/submit

) Biomed Central 